\title{
Impact of Kangaroo Mother Care on Outcome of Very Low Birthweight Preterm Newborns in a Tertiary Hospital in Abakaliki, Nigeria
}

\section{Obumneme Ezeanosike1,2, Olapeju Daniyan', Onyinyechukwu Anyanwu', Uzoma Asiegbu ${ }^{1,2}$, Chinonyelum Ezeonu ${ }^{1,2}$, Emeka Onwe-Ogah ${ }^{1,2}$ and Onyire Onyire ${ }^{1,2}$}

${ }^{1}$ Department of Paediatrics, Alex Ekwueme Federal University Teaching Hospital, Abakaliki Ebonyi State, Nigeria

${ }^{2}$ Department of Paediatrics, Ebonyi State University, Abakaliki, Ebonyi State, Nigeria

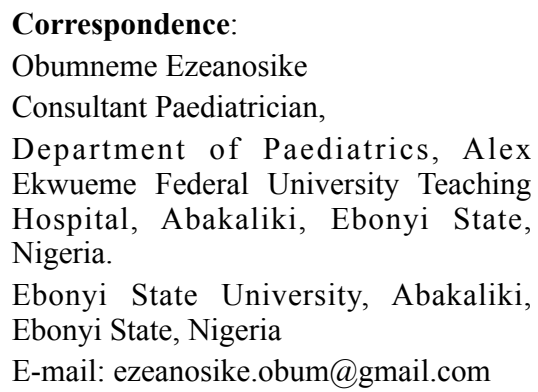

DOI: $10.3126 /$ jnps.v39i2.26269

Submitted on: 2019-11-08

Accepted on: 2020-03-26

\section{Acknowledgements: None}

Funding: Nil

Conflict of Interest: None declared

Permission form IRB: Yes

To cite this article: Ezeanosike $\mathrm{O}$, Daniyan O, Anyanwu O, Asiegbu U, Ezeonu C, Onwe-Ogah E, Onyire O. Impact of kangaroo mother care on outcome of very low birthweight preterm newborns in a tertiary hospital in Abakaliki, Nigeria. J Nepal Paediatr Soc. 2019;39(2):95-102.

\section{ABSTRACT}

Introduction: KMC was developed for care of preterm and low birth weight babies due to shortage of staff and inadequate incubator care enabling early discharge from the hospital for close follow-up at home. It is essential in resource-limited countries where there is epileptic power supply. Therefore, strengthening the evidence for KMC becomes imperative in these resource-limited and adverse cultural regions.

Methods: The KMC register of the Newborn Special Care Baby Unit of a tertiary hospital was used to analyse records from January 2016 to February 2018. A total of 55 preterm babies enrolled into KMC were studied. The age and parity of the mother, sex, birth weight, admission and discharge temperatures and weights, duration of KMC per day was retrieved from the KMC register.

Results: The mothers' ages ranged from 18 to 40 years (mean 28.6 \pm 6.2 years) with $34 \%$ being inexperienced first-time mothers and $10 \%$ grand multipara. The birth weights of the babies ranged from $0.9 \mathrm{~kg}$ to $2.5 \mathrm{~kg}$. Primiparous women were more likely to do KMC for longer durations. A linear regression model showed that the duration of KMC was related to parity. $\left(\mathrm{R}^{2}=0.12, \mathrm{p}=0.02\right)$. On average there was significant weight gain on discharge with a paired t-test $(\mathrm{t}=5.881$, $\mathrm{df}=44)$ comparing the discharge and commencement weights showing a mean difference of $0.123 \mathrm{~kg}$ (CI $0.081 \mathrm{~kg}, 0.165 \mathrm{~kg}, \mathrm{p}<0.001)$.

Conclusions: KMC impacts positively on all parameters of the extremely LBW and premature babies and the duration of KMC is positively associated with better outcome.

Key Words: Kangaroo mother care; newborn; skin-to-skin

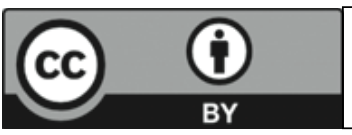

This work is licensed under creative common attribution 3.0 license 


\section{INTRODUCTION}

The World Health Organisation defines four components of Kangaroo Mother Care (KMC) to include: early continuous and prolonged skin-toskin contact (SSC) between the newborn and mother, exclusive breastfeeding, early discharge from the health facility and close follow-up at home. ${ }^{1}$

KMC was first presented by Rey and Martinez in Bogotá, Colombia, where it was developed for the care of preterm and low birth weight babies due to shortage of staff and inadequate incubator care. ${ }^{2,3}$ It is therefore essential in resource-poor countries where epileptic power supply affects the optimal functioning of the incubators. ${ }^{4} \mathrm{~A}$ systematic review done by Lawn JE et al. showed that KMC substantially reduces neonatal mortality amongst preterm babies (birth weight $<2000 \mathrm{~g}$ ) in hospital and is highly effective in reducing severe morbidity. ${ }^{5}$ It also provides effective thermal control and encourages exclusive breastfeeding. 6,7 It has been found to be more parent and babyfriendly because it encourages maternal and infant bonding than the conventional incubator care where the baby is separated from the mother. ${ }^{6}$ Studies have shown that it improves oxygen saturation and other vital physiological parameters. ${ }^{8-10}$

In some situations there are adverse cultural scenarios, and/or poor family-income-motivated request for early discharge against medical advice even for very low birthweight newborns. This may be related to the need to care for other children at home, loss of productivity by the mothers who are co-bread winners and more often, in our environment, women are key providers of manual labour for masonry and in the local quarry and rice farms. Others include the need to cohabit with their husbands who are key decision makers for the families' health seeking behaviours. Thus, KMC helps small babies to be discharged early. It is initiated in the hospital and can be continued at home where the mothers can be minimally useful while carrying the babies in KMC position. The most important resources for KMC therefore, are the mother, trained personnel with skills to initiate and manage the baby in $\mathrm{KMC}$ and a supportive environment. ${ }^{11,12}$ The support binder is from a soft fabric, which when applied binds the baby firmly to the mother chest. ${ }^{13}$ Therefore, strengthening the evidence for $\mathrm{KMC}$ becomes imperative in these resource-limited and adverse cultural regions.

There is currently dearth of published data on KMC in the study area. Therefore, the aim of this study was to determine pattern and to examine outcome of kangaroo mother care at the Newborn Special Care Baby Unit of a tertiary facility.

\section{METHODS}

This was a retrospective study carried out at the Newborn Special Care Baby Unit (NBSCU) of a tertiary hospital from January 2016 to February 2018. The NBSCU has an in-born and out-born units with an average yearly neonatal admission of 275 neonates. The unit has a KMC room allocated for mothers to practice $\mathrm{KMC}$ and breastfeed their babies. There is a KMC register for all babies who had $\mathrm{KMC}$, a total of 55 preterm babies who were enrolled into KMC were studied. Information about the age and parity of the mother, birth weight of the baby, sex of the baby, temperature readings on admission and discharge, date of commencement of $\mathrm{KMC}$, duration of $\mathrm{KMC}$, date discharge from $\mathrm{KMC}$ and outcomes were retrieved from the KMC register.

\section{RESULTS}

A total of 55 preterm neonates who were registered for KMC were studied and data analyzed. The age range of the mothers and their parity is shown in Table 1. Twenty-seven percent of the mothers were aged between 25 to 29 years. Figure 1 shows the place and mode of delivery of the babies who were placed in KMC in our facility. Thirty-three $(60 \%)$ babies had spontaneous vaginal delivery.

A summary statistics of the babies is as shown in Table 2. There were 22 females and 33 males. A two-sample $\mathrm{t}$-test with equal variances $(\mathrm{t}=1.149$, $\mathrm{df}=47$ ) showed that there was no significant difference between the weights of the females compared to the weights of males at the commencement of the KMC $(p=0.256)$. A paired $\mathrm{t}$-test $(\mathrm{t}=5.881, \mathrm{df}=44)$ comparing the weights on discharge to the weights at commencement showed 
Table 1. Tabulation of mothers' ages and parity

\begin{tabular}{|c|c|c|}
\hline & Frequency & Percentage (\%) \\
\hline \multicolumn{3}{|l|}{ Age group (yrs) } \\
\hline $15-19$ & 2 & 4.2 \\
\hline $20-24$ & 9 & 18.7 \\
\hline $25-29$ & 13 & 27.1 \\
\hline $30-34$ & 13 & 27.1 \\
\hline $35-39$ & 10 & 20.8 \\
\hline $40-44$ & 1 & 2.1 \\
\hline \multicolumn{3}{|l|}{ Parity } \\
\hline$<2$ & 19 & 38.7 \\
\hline $2-4$ & 26 & 53.1 \\
\hline$>5$ & 4 & 8.2 \\
\hline
\end{tabular}

a significant mean difference of $0.123 \mathrm{~kg}$ (CI 0.081 $\mathrm{kg}, 0.165 \mathrm{~kg}, \mathrm{p}<0.001)$.

A series of one-way ANOVA were also conducted to determine if birth weight, temperature on admission, temperature on discharge and discharge weight, were different between the males and females. There were no statistically significant difference between the sexes as determined by the one-way ANOVA for birth weight, $(\mathrm{F}(1,53)=2.61$, $\mathrm{p}=.112)$; temperature on admission, $(\mathrm{F}(1,53)=$ $0.05, \mathrm{p}=.830)$; temperature on discharge, $(\mathrm{F}(1,47)$ $=0.02, \mathrm{p}=.882)$; and, discharge weight, $(\mathrm{F}(1,43)$ $=0.26, \mathrm{p}=.609$ ).

The temperature readings of the babies are as shown in Figure 3. About $73 \%$ of the babies had subnormal temperatures from below $36.5^{\circ} \mathrm{C}$ to $35^{\circ} \mathrm{C}$ on admission into $\mathrm{KMC}$, irrespective of the sex, birthweight or admission weight of the baby. On discharge, there were significant improvements in the temperature readings of all the babies. A paired $\mathrm{t}$-test $(\mathrm{t}=9.126, \mathrm{df}=48)$ was also carried out to compare the discharge temperature readings to the temperature on commencement of the KMC. It showed a mean gain in temperature of $1.13^{\circ} \mathrm{C}$, which was significant $(\mathrm{p}<0.001)$. The average daily duration of KMC by the mothers is shown in Table 3. The minimum daily duration of KMC was two hours.

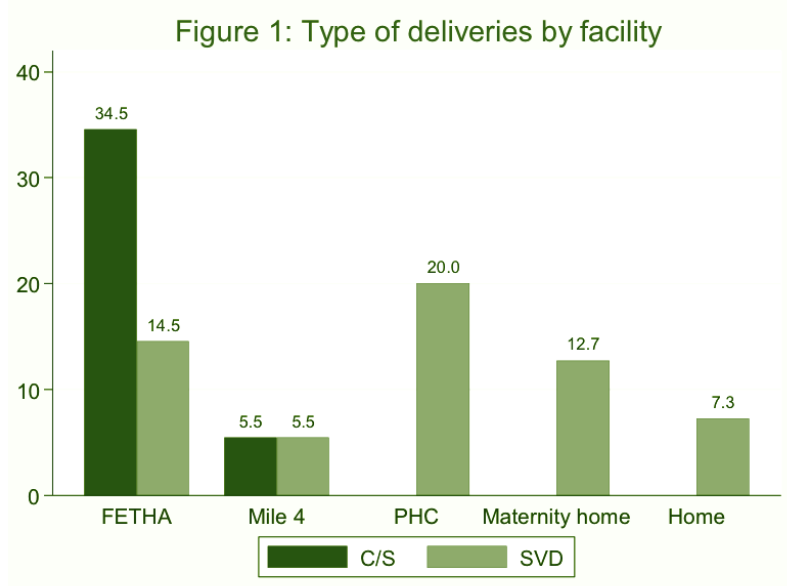

Figure 1. Type of deliveries by facility

A linear regression showed that twelve percent of the variance in KMC duration can be explained by the parity of the women $(\mathrm{R} 2=0.12)$ and the pvalue of the model showed that the relationship was statistically significant $(\mathrm{p}=0.02)$. The primiparous women were more likely to do KMC for longer daily durations as shown in the scatter plot in Figure 4. The outcomes of babies who had KMC are shown in Table 3. Forty-seven (92.2\%) of the babies were discharged alive to continue homebased KMC.

\section{DISCUSSION}

$\mathrm{KMC}$ is an innovation that was developed to improve the outcome of preterm babies especially in developing countries. The mothers' ages in our cohort ranged from 18 to 45 years covering the active female reproductive years. The majority were between 25 and 34 years. Their parities also varied from being primiparous to grand multipararous. The age of the mothers may be a reflection of the mothers who gave birth to preterm babies in the study area during the period since most of the mothers were willing to carry out the KMC including the teenage mother. The association between maternal age and preterm deliveries remains controversial. ${ }^{14}$ However, after adjusting for potential confounders, Fuchs et al. found that advanced maternal age was associated with more preterm birth, with the lowest risk being between 30 to 34 years. They also found that the younger mothers below 24 years tend to have higher preterm births compared to the 30 to 34 year 
Table 2. Summary Statistics by sex of the babies in $\mathrm{KMC}$

\begin{tabular}{|c|c|c|c|c|c|c|}
\hline Females & $\mathbf{N}$ & Mean & SD & p5 & p10 & p25 \\
\hline Birth weight & 22 & 1.5 & 0.5 & 1 & 1 & 1.1 \\
\hline $\begin{array}{l}\text { Admission } \\
\text { weight }\end{array}$ & 18 & 1.5 & 0.5 & 0.9 & 1 & 1.2 \\
\hline $\begin{array}{l}\text { Discharge } \\
\text { weight }\end{array}$ & 16 & 1.6 & 0.4 & 1.2 & 1.2 & 1.3 \\
\hline $\begin{array}{l}\text { Admission } \\
\text { temperature }\end{array}$ & 22 & 35.8 & 1 & 35 & 35 & 35 \\
\hline $\begin{array}{l}\text { Discharge } \\
\text { temperature }\end{array}$ & 19 & 36.8 & 0.3 & 36.2 & 36.4 & 36.7 \\
\hline \multicolumn{7}{|l|}{ Males } \\
\hline Birth weight & 33 & 1.3 & 0.2 & 0.9 & 1 & 1.2 \\
\hline $\begin{array}{l}\text { Admission } \\
\text { weight }\end{array}$ & 31 & 1.4 & 0.2 & 1.1 & 1.2 & 1.3 \\
\hline $\begin{array}{l}\text { Discharge } \\
\text { weight }\end{array}$ & 29 & 1.5 & 0.2 & 1.3 & 1.4 & 1.4 \\
\hline $\begin{array}{l}\text { Admission } \\
\text { temperature }\end{array}$ & 33 & 35.9 & 0.9 & 35 & 35 & 35 \\
\hline $\begin{array}{l}\text { Discharge } \\
\text { temperature }\end{array}$ & 30 & 36.8 & 0.2 & 36.5 & 36.6 & 36.6 \\
\hline
\end{tabular}

age group. ${ }^{14}$ Lumbanraja ${ }^{15}$ also noted that maternal age did not influence the outcome of KMC.
Most (34\%) of the participants in our study were first time mothers. The mother's ability and capacity to detect and respond to the newborn baby's behavioural signals during care interactions is a critical aspect of mother-infant bonding and this is influenced by parity. It is of particular concern when preterm babies are nursed by inexperienced first-time mothers. There may be heightened anxiety and fear among these young mothers leading to a wide range of possibilities. Some may respond with more care towards their precious babies while others may respond with trepidation and fear and might abandon the KMC. Our first-time mothers participated well and more, possibly because of the well-established impact of kangaroo care social support provided by the group practice of KMC together with other mothers in our Kangaroo Mother care room. ${ }^{16}$ Our study also showed that the primiparous women were more likely to do KMC for longer daily durations with one primiparous woman averaging 14 hours a day compared to the grand multiparous women where some did as little as two hours on average per day. The linear regression showed that duration of KMC in our study was related to the parity of the women $\left(\mathrm{R}^{2}=0.12\right)$ and the $\mathrm{p}$-value of the model was statistically significant $(p=0.02)$. Other competing

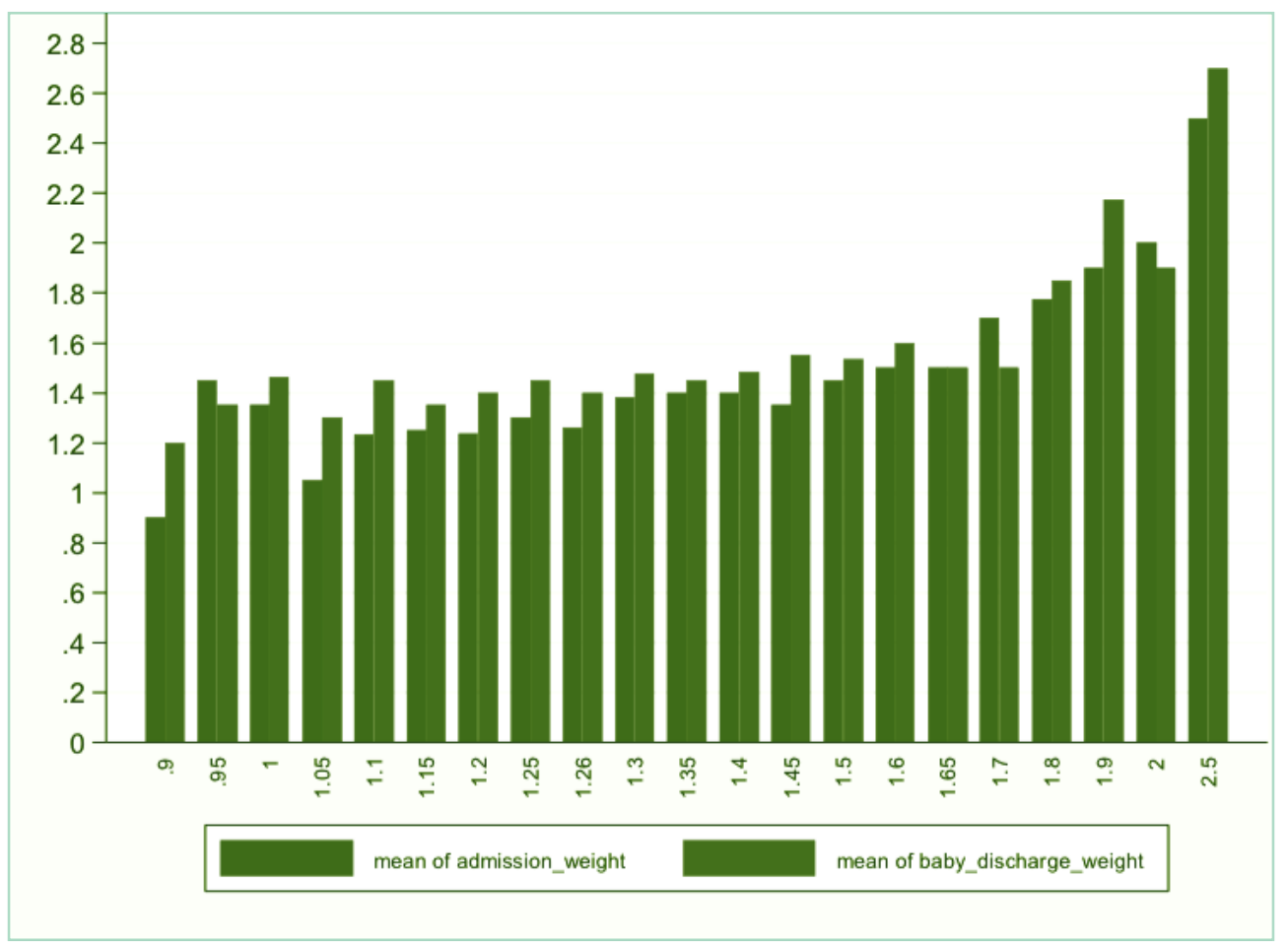

Figure 2. Graph showing increase in discharge weights from admission weights 

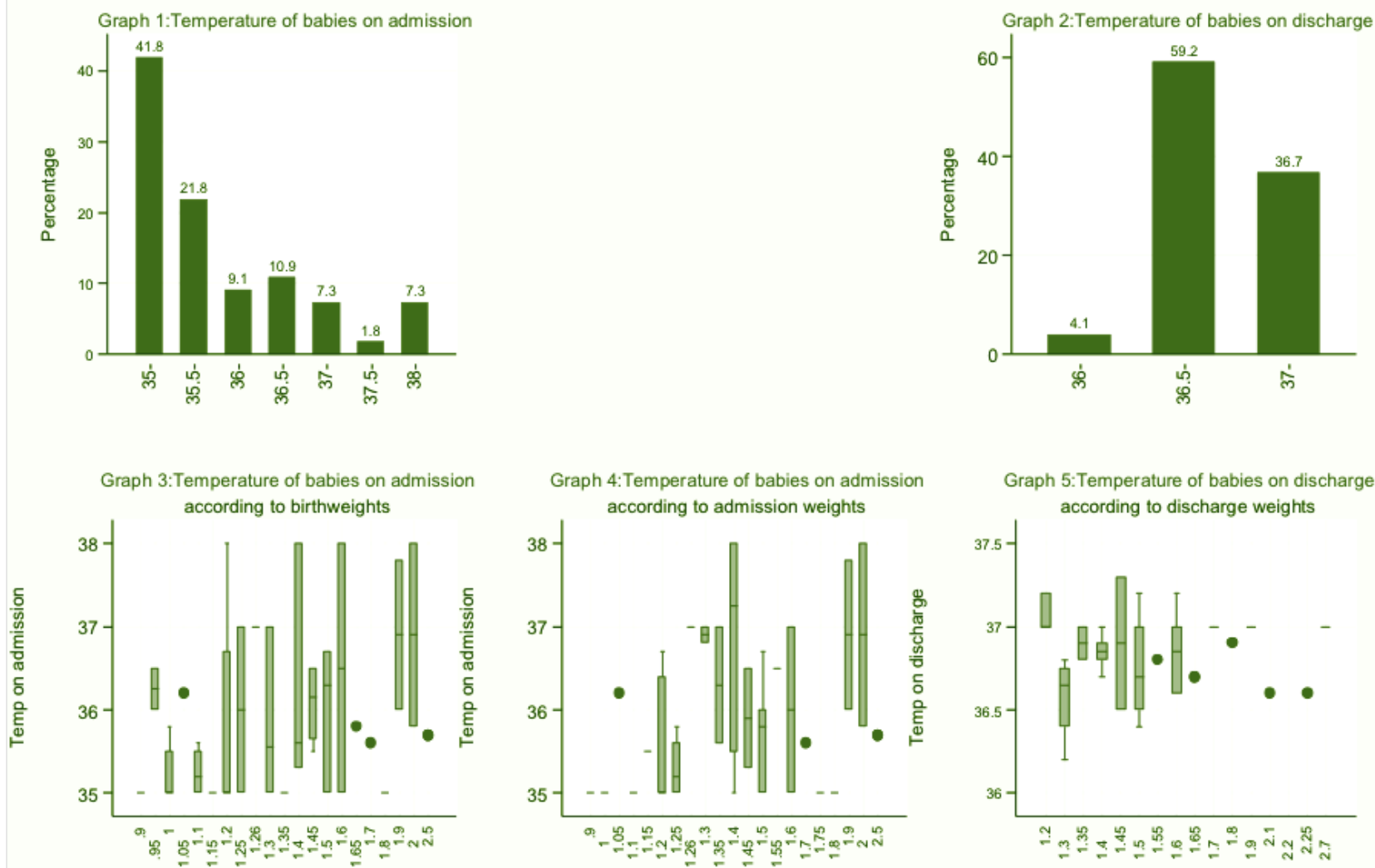

Figure 3. Graph of temperature changes in babies in KMC

interests in the lives of the higher parity women may have affected their participation in and the duration of KMC. Parenting of older siblings and exacting family responsibilities may affect maternal responsiveness and in-patient caregiving by mothers of higher order parity and this may explain the duration of about two hours by the Para eight mother.

The sex of the babies did not affect any parameter or outcome of KMC in our study even though there was excess in the number of males (33 versus 22 ). Several studies ${ }^{17-19}$ show an excess in the proportion of boys among preterm births. Zeitlin et al. found the same in a review with an odds ratio 1.09-1.24. ${ }^{20}$ The Impact of Foetal Gender on the Risk of Preterm study concluded that male foetuses were at increased risk of spontaneous preterm birth as well as preterm premature rupture of membranes in a wide range of populations across time and space. ${ }^{21}$

Most of the babies in our study weighed between 1 to $1.9 \mathrm{~kg}$. This agrees with the Nigerian National KMC guideline recommendation to place all stable newborn babies below $1.8 \mathrm{~kg}$ in $\mathrm{KMC}$ especially in secondary health care facilities. ${ }^{22}$ When stabilised, KMC can be continued at home. The primary health care facilities in the study area are not fully equipped to take care of preterm babies including providing facility based continuous $\mathrm{KMC}$ and other comprehensive neonatal care. This explains why most out-born babies of our cohort were referred from primary health care facilities. The maternity homes contributed the second highest proportion of out-born referrals into our Kangaroo Mother care as they do not have the capacity to manage preterm babies.

The referral system in a Kangaroo Mother Care Program should be a bilateral referral system where babies born preterm at maternity homes and primary health care facilities are referred to tertiary care and after commencement of facility based continuous KMC, stabilisation of the babies, they should be back-referred to the secondary and primary health care facilities from where they came for supervision of either a home-based KMC or daily visit to the primary health care centre. 
Table 3. Duration of KMC and Outcome of babies in $\mathrm{KMC}$

\begin{tabular}{|clr|}
\hline & Frequency & Percentage \\
\hline $\begin{array}{l}\text { Average daily KMC } \\
\text { duration (hrs) }\end{array}$ & & \\
2 & 4 & 8.9 \\
3 & 1 & 2.2 \\
4 & 11 & 24.4 \\
6 & 11 & 24.4 \\
8 & 16 & 35.6 \\
10 & 1 & 2.2 \\
14 & 1 & 2.2 \\
Outcome & & 92.2 \\
Alive & 47 & 7.8 \\
Dead & 4 &
\end{tabular}

Home deliveries are not encouraged in the study area and especially, preterm delivery portend enormous risk to the life of the baby (and the mother). About seven percent of our cohort came from home deliveries.

Concerning the weight of the babies, $59 \%$ weighed between 1.0 and $1.4 \mathrm{~kg}$ at commencement of KMC, but, on average the babies gained significant weights on discharge from the facility with a paired t-test $(\mathrm{t}=5.881, \mathrm{df}=44)$ comparing the weights on discharge to the weights at commencement showing a mean difference of $0.123 \mathrm{~kg}$ (CI $0.081 \mathrm{~kg}, 0.165 \mathrm{~kg}, \mathrm{p}<0.001$ ). Some other study ${ }^{23}$ demonstrated a better comparative Kangaroo Mother Care to Conventional Methods of Care (CMC) average daily weight gain per day among the infants. (KMC: $23.99 \mathrm{~g}$ vs CMC: 15.58 g, $\mathrm{P}<0.0001)$. Samra et al. also showed that KMC with additional opportunities to breastfeed was found to be an effective intervention for LBWs with delayed weight gain and should be considered to be an effective strategy. ${ }^{24}$

Temperature instability is a major problem in the preterm and $73 \%$ of our cohort had temperatures below $36.5^{\circ} \mathrm{C}$ on admission irrespective of the sex, birth weight or admission weight of the baby. There were significant improvements in the temperature

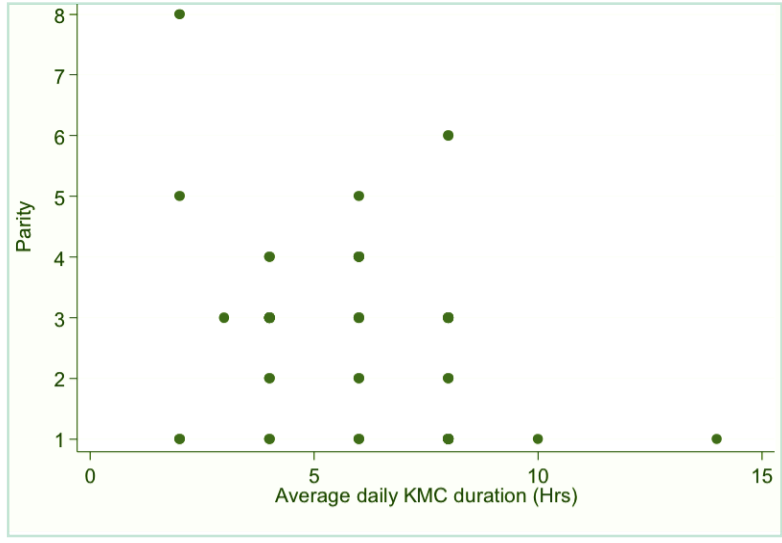

Figure 4. Scatter plot of parity of mothers versus duration of $\mathrm{KMC}$

readings of all the babies discharged with a mean gain of $1.13^{\circ} \mathrm{C}$. Skin-to-Skin care (SSC) in KMC improves the body temperature of the preterm newborn with minimal fluctuations especially when there is prolonged continuous skin to skin care.

Bauer et al. ${ }^{25}$ showed that for stable preterm infants weighing less than $1500 \mathrm{gm}$ and less than one week of age, one hour of skin-to-skin care is not a cold stress compared with care in a thermo neutral incubator. Indeed, they showed that during skin-toskin care the mean rectal temperature was $0.2^{\circ} \mathrm{C}(\mathrm{p}$ $<0.01)$ and the peripheral skin temperature was $0.6^{\circ} \mathrm{C}(\mathrm{p}<0.01)$ higher than during the preceding hour in the incubator while Karlsson showed that during SSC, the conduction of heat from parent to infant is sufficiently high to compensate for the increase in evaporative and convective heat loss. ${ }^{26}$ The increased water loss through the skin during SSC is small and should not affect the infant's fluid balance. ${ }^{26}$

About $84 \%$ of the mothers carried out intermittent KMC versus continuous KMC, carrying their babies skin to skin for about four to eight hours daily. The duration of KMC is positively associated with good outcome, with better outcomes and benefits derived from the longer continuous KMC. This more intermittent versus continuous KMC in our study may have been occasioned by limited bed space, other competing in patient care demands for the baby, stress for the mother relating to the nonconducive hospital environment, other home care needs including care for other siblings especially 
for higher order parity mothers and for some, limited family support especially for those lacking the support of the husbands. Despite all these, KMC was shown in this study to lead to improved and better outcomes for the preterm babies especially in our environment with limiting medical and financial resources. In the long run it also promotes maternal and infant bonding and encourages exclusive breastfeeding.

\section{CONCLUSIONS}

$\mathrm{KMC}$ has been shown to impact positively on all parameters of the extremely low birth weight and premature babies and the duration of $\mathrm{KMC}$ is positively associated with better outcome, enabling early discharge at low weights for continuation of home-based KMC.

\section{REFERENCES}

1. Boundy EO, Dastjerdi R, Spiegelman D, Fawzi WW, Missmer SA, Lieberman E, et al. Kangaroo mother care and neonatal outcomes: a meta-analysis. Pediatrics. 2016 Jan;137(1):e20152238. DOI:10.1542/peds.2015-2238

2. Sharma D, Farahbakhsh N, Sharma S, Sharma P, Sharma A. Role of kangaroo mother care in growth and breast feeding rates in very low birth weight (VLBW) neonates: a systematic review. J Matern Fetal Neonatal Med. 2019; 32:129-42. DOI: 10.1080/14767058.2017.1304535

3. Charpak N, Ruiz-Peláez JG, Charpak Y. Rey-Martinez Kangaroo Mother Program: An Alternative Way of Caring for Low Birth Weight Infants? One Year Mortality in a Two Cohort Study. Pediatrics. 1994;94:804-10

4. Adair-Rohani H, Zukor K, Bonjour S, Wilburn S, Kuesel AC, Hebert R, et al. Limited electricity access in health facilities of sub-Saharan Africa: a systematic review of data on electricity access, sources, and reliability. Glo health sci and pract. 2013;1:249-61. DOI:http://dx.DOI.org/10.9745/GHSP-D-13-00037

5. Lawn JE, Mwansa-Kambafwile J, Horta BL, Barros FC, Cousens S. Kangaroo mother care to prevent neonatal deaths due to preterm birth complications. Int J Epidemiol. 2010;39:144-54. DOI: 10.1093/ije/dyq031

6. Ibe OE, Austin T, Sullivan K, Fabanwo O, Disu E, Costello AM. A comparison of kangaroo mother care and conventional incubator care for thermal regulation of infants $<2000 \mathrm{~g}$ in Nigeria using continuous ambulatory temperature monitoring. Ann Trop Paediatr. 2004;24:245-51. DOI: 10.1179/027249304225019082

7. Heidarzadeh M, Hosseini MB, Ershadmanesh M, Gholamitabar Tabari M, Khazaee S. The Effect of Kangaroo Mother Care (KMC) on Breast Feeding at the Time of NICU Discharge. Iran Red Crescent Med J. 2013;15:302-6. DOI: $10.5812 /$ ircmj. 2160

8. Bera A, Ghosh J, Singh AK, Hazra A, Som T, Munian D. Effect of kangaroo mother care on vital physiological parameters of the low birth weight newborn. Indian J Community Med. 2014;39:245-9. DOI: 10.4103/0970-0218.143030

9. Stuard W. The effects of kangaroo care on a newborn development and vital physiology. Clin Mother Child Health. 2016;13:1. DOI:10.4172/2090-7214.1000225

10. Parsa P, Karimi S, Basiri B, Roshanaei G. The effect of kangaroo mother care on physiological parameters of premature infants in Hamadan City, Iran. Pan Afr Med J. 2018;30:89. DOI:1011604/pamj2018.30.89.14428

11. Campbell-Yeo ML, Disher TC, Benoit BL, Johnston CC. Understanding kangaroo care and its benefits to preterm infants. Pediatric Health Med Ther. 2015;6:15-32. DOI: 10.2147/PHMT.S51869

12. Bergh AM, Charpak N, Ezeonodo A, Udani R, van Rooyen E. Education and training in the implementation of kangaroo mother care. S Afr J Child Health 2012;6: 38-45. DOI: 10.7196/SAJCH.417

13. Kampekete GSM, Ngoma C, Masumo M. Acceptance of kangaroo mother care by mothers of premature babies. Afr J Midwifery Womens Health 2018; 12:178-88. DOI: https://doi.org/10.12968/ajmw.2018.12.4.178

14. Fuchs F, Monet B, Ducruet T, Chaillet N, Audibert F. Effect of maternal age on the risk of preterm birth: A large cohort study. PLoS ONE 2018;13:e0191002. DOI: 10.1371/journal.pone.0191002

15. Lumbanraja SN. Influence of maternal factors on the successful outcome of kangaroo mother care in low birthweight infants: A randomised controlled trial. J Neonatal Perinatal Med. 2016;9:385-92. DOI: 10.3233/NPM-161628 
16. Chan G, Bergelson I, Smith ER, Skotnes T, Wall S. Barriers and enablers of kangaroo mother care implementation from a health systems perspective: a systematic review. Health Policy Plan. 2017;32:1466-75. DOI:10.1093/heapol/ czx098

17. Astolfi P, Zonta LA. Risks of preterm delivery and association with maternal age, birth order, and fetal gender. Hum Reprod. 1999;14:2891-4. DOI.10.1093/humrep/14.11.2891

18. Hall MH, Carr-Hill R. Impact of sex ratio on onset and management of labour. Br Med J. 1982;285:401-3. DOI: 10.1136/bmj.285.6339.401

19. Cooperstock M, Campbell J. Excess males in preterm birth: interactions with gestational age, race, and multiple birth. Obstet Gynecol. 1996;88:189-93. DOI: 10.1016/0029-7844(96)00106-8

20. Zeitlin J, Saurel-Cubizolles M-J, de Mouzon J, Rivera L, Ancel P-Y, Blondel B, et al. Fetal sex and preterm birth: are males at greater risk? Hum Reprod. 2002;17:2762-8. DOI: 10.1093/humrep/17.10.2762

21. Peelen MJ, Kazemier BM, Ravelli AC, De Groot CJ, Van Der Post JA, Mol BW, et al. Impact of foetal gender on the risk of preterm birth, a national cohort study. Acta Obstet Gynecol Scand. 2016;95:1034-41. DOI: https:// DOI.org/10.1111/aogs.12929

22. Ezeanosike OB, Bello M, James OI, Adeboye MA, Adeniran AR, Ezeaka VC, et al. Federal Ministry of Health Nigeria. Essential Care for Every Baby Provider Guide for Module 3.2016.

23. Suman RP, Udani R, Nanavati R. Kangaroo mother care for low birth weight infants: a randomized controlled trial. Indian Pediatr 2008; $45: 17-23$.

24. Samra NM, Taweel AE, Cadwell K. Effect of intermittent kangaroo mother care on weight gain of low birth weight neonates with delayed weight gain. J Perinat Educ. 2013;22:194-200. DOI:10.3109/14767058.2011.634459

25. Bauer K, Uhrig C, Sperling P, Pasel K, Wieland C, Versmold HT. Body temperatures and oxygen consumption during skin-to-skin (kangaroo) care in stable preterm infants weighing less than 1500 grams. J Pediatr. 1997;130:240-4. DOI:10.1016/s0022-3476(97)7034-4

26. Karlsson V, Heinemann AB, Sjors G, Nykvist KH, Agren J. Early skin-to-skin care in extremely preterm infants: thermal balance and care environment. J Pediatr. 2012;161:422-6. DOI:10.1016/j.jpeds.2012.02.034 